\title{
ANÁLISE TEXTUAL DISCURSIVA: ENTRE A ANÁLISE DE CONTEÚDO E A ANÁLISE DE DISCURSO
}

\section{DISCURSIVE TEXTUAL ANALYSIS: BETWEEN CONTENT ANALYSIS AND DISCOURSE ANALYSIS}

\author{
Gleny Terezinha Duro Guimarães ${ }^{1}$ \\ Marlúbia Corrêa de Paula ${ }^{2}$
}

\begin{abstract}
Resumo: Este artigo reflete sobre o entrelugar em que se situa a Análise Textual Discursiva (ATD) em relação à Análise de Conteúdo (AC) e à Análise de Discurso (AD). Trata-se de um estudo teórico com pesquisa empírica, estruturado em cinco seções. Primeiro, partimos da origem na distinção entre idealistas e materialistas para então caracterizar as fases de produção teórica de Moraes (primeira e segunda fase). Em seguida, procuramos caracterizar o termo discurso na ATD, defendendo a ideia de que existe um duplo significado: o discurso social e o discurso textual. Posteriormente, realizamos uma distinção entre autores que influenciam os estudos do discurso e teóricos da Análise de Discurso. Por fim, apresentamos alguns aspectos do dispositivo teórico e analítico da $\mathrm{AD}$ da linha francesa. Concluimos que entre as duas extremidades em que se situa a ATD, existem distinções epistemológicas.
\end{abstract}

Palavras-chave: Análise Textual Discursiva; Análise de Discurso; Análise de Conteúdo.

\begin{abstract}
This paper reflects on the in-between spaces in which the Discursive Textual Analysis (DTA) is found in relation to the Content Analysis (CA) and Discourse Analysis (DA). It is a theoretical study with empirical research, structured in five items. It starts upon the distinction of idealists and materialists, to characterize the phases of the theoretical production by Moraes as early and late stages. Then, we conceptualize the term discourse at the DTA, on the idea that there is a twofold meaning: social discourse, and textual discourse. Later, the paper distinguishes amongst discourse study and discourse analysis theorists. Finally, the work presents some aspects of the theoretical and analytical device of DA according to its French branch. It finishes by saying that, between the two poles in which DTA is found, there exist epistemological distinctions.
\end{abstract}

Keywords: Discursive textual analysis; Discourse analysis; Content analysis.

\section{Introdução}

Dizer "análise textual discursiva", doravante referida como ATD, implica numa série de referências epistemológicas próprias a cada um dos termos utilizados. Em decorrência disso, Moraes e Galiazzi (2007) realizam, de modo intencional, escolhas ao

\footnotetext{
${ }^{1}$ Pós-doutora pela Universidade Católica de Lisboa UCL e Doutora pela PUCSP. Professora na gradução em curso de Serviço Social. Docente nos Programas de Pós-Graduação em Educação em Ciências e Matemática - PPGEDUCEM; Programa de Serviço Social - PPGSS - Pontifícia Universidade Católica do Rio Grande do Sul - PUCRS, Porto Alegre, RS, Brasil. E-mail: gleny@pucrs.br

${ }^{2}$ Doutora pela PUCRS. Docente no Programa de Pós-Graduação em Educação em Ciências e Matemática - PPGECM - Professora na Graduação em curso de Licenciatura em Matemática e Agronomia Universidade Estadual de Santa Cruz - UESC. Ilhéus, Bahia, Brasil. E-mail: mcpaula@uesc.br
} 
empregar essa terminologia. A "análise textual" diz respeito ao processo analítico de um texto em que uma mensagem - ou tipo de comunicação - está sendo veiculada. Predominantemente, a expressão diz respeito às mais diversas formas de comunicação e de linguagem, que podem ser analisadas sob a forma de texto. Seu oposto é pensar nas técnicas não textuais "como sistemas expressivos como arquitetura, decoração, moda" (NAVARRO; DÍAZ, 1994, p. 179). Nesse sentido, o texto pode ser considerado como toda forma textual que expressa uma comunicação.

Quando nos deparamos com o termo "discursivo", surge um questionamento: Qual o significado a ele atribuído? Como a ATD o utiliza? Existe aí alguma especificidade? Será que o termo se relaciona com as abordagens caracterizadoras das Análises de Discursos (AD)? Eis as questões que norteiam as reflexões do presente artigo.

Partimos, inicialmente, das condições em que se produz nosso "discurso", os fatores que influenciam nossa interlocução, e que se relacionam com um percurso histórico. Após a constatação de que os discentes da pós-graduação geralmente apresentavam dificuldades em relação à forma como se analisam os dados na pesquisa qualitativa, em 2000, foi criada a disciplina “Análise de Discurso e Análise de Conteúdo", oferecida pelo Programa de Pós-Graduaçao em Serviço Social da PUCRS. O objetivo da nova cadeira era o de proporcionar uma visão geral dos vários tipos de análise existentes, que poderiam ser escolhidos pelos pesquisadores. Esta disciplina tinha um cunho teóricoprático, pois, na medida em que as teorias eram apresentadas, eram realizados os exercícios de análises. Isso possibilitava aos discentes-pesquisadores escolherem o tipo de análise que correspondesse ao seu objeto de pesquisa, uma vez que dispunham de um repertório que ia além da tradicional escolha pela Análise de Conteúdo de Bardin.

Sempre que possível, o Prof. Dr. Roque Moraes era convidado a participar de uma das aulas da disciplina destinada ao estudo da ATD. Foi em uma destas ocasiões, que perguntamos se poderíamos dizer "Moraes primeira fase" e "Moraes segunda fase" ao nos referirmos às distintas fases de sua produção teórica. Nesse momento, ao expressar um sorrisinho surpreso, ele respondeu: "Pode!". Assim, a partir daquela data, estávamos autorizadas a usar tal nomenclatura. Na primeira fase, referiamo-nos à produção da década de 1990, época em que o autor se baseava na Análise de Conteúdo (AC) de base bardiniana; ainda que, simultaneamente, já apresentasse uma proposta diferenciada, principalmente em relação ao processo de categorização. A segunda fase, que ocorre a partir da década de 2000, é aquela em que o Prof. Dr. Roque Moraes se dedica à ATD, em parceria com a Profa. Dra. Maria do Carmo Galiazzi. Sem dúvidas, as duas fases se 
complementavam; mas, ao mesmo tempo, a segunda representava uma nova proposta analítica.

Entre a AC, da primeira fase, e a ATD, da segunda fase, existem semelhanças e diferenças. Ter como parâmetro estas peculiaridades nos auxilia a estabelecer referenciais para identificar possibilidades de aproximação entre os tipos de análise. É importante lembrarmos que a ATD "assume pressupostos que a localizam entre os extremos da AC e AD” (MORAES; GALIAZZI, 2007, p. 140). Para melhor compreendermos este meiolugar em que se encontra a ATD, é preciso investigar seu percurso, desde sua origem na $\mathrm{AC}$ até seu distanciamento, o que possibilita trilhar outros rumos. Nesse sentido, a primeira questão com a qual nos deparamos é: quais são os extremos utilizados para estabelecer este intervalo analítico? E, além disso, o que significa dizer que a ATD está entre dois extremos?

Para responder a estas questões, partimos do pressuposto de que o ponto de origem, digamos, o ponto A, é a AC com base em Bardin; por outro lado, o ponto B, no outro extremo, corresponde à $\mathrm{AD}$ de linha francesa, de Michel Pêcheux. Neste intervalo, poderíamos dizer que existem muitas outras formas de análise que, juntamente com a ATD, apresentam distanciamentos e afastamentos dos referidos polos A e B. Por que, no entanto, estamos considerando especificamente estas duas abordagens como extremos, na medida em que existem outras abordagens teóricas de AD?

Porque entendemos que a $\mathrm{AC}$ de Bardin aponta para um processo fechado, enquanto a AD de Pêcheux, para um processo aberto, um representando o oposto do outro. Dizemos "fechado" no sentido da AC estabelecer as etapas metodológicas a priori e, a partir daí, possibilitar a escolha de diversos aportes teóricos; trata-se de uma técnica que se aplica a partir de etapas previamente estabelecidas. Um processo "aberto", por outro lado, não estabelece nenhuma etapa metodológica prévia, pois a análise é conduzida pelo dispositivo teórico e, dialeticamente, este dispositivo é (retro)construído pela análise. De fato, duas extremidades marcadas por diferenças metodológicas e epistemológicas.

Mas ainda fica uma questão: a diferença entre as metodologias é suficiente para demarcar polos extremos? Diríamos que não e, para compreender de fato onde está a demarcação dessas extremidades, temos que entender a origem filosófica que subjaz as duas grandes vertentes que originam tais concepções, distintas em relação à concepção de mundo, de ser e de sociedade. Estamos nos referindo às bases filosóficas que vão se modificando com o desenvolvimento da ciência e que representam perspectivas 
antagônicas; ou seja, dependendo da concepção de origem, a compreensão e interpretação da realidade, dos fenômenos, objetos, consciência, matéria, tornam-se diferentes.

Quando nos referimos à questão original, referimo-nos à pergunta filosófica: quem vem primeiro, a realidade da consciência ou a realidade material? A resposta para esta questão fundamental originou duas bases filosóficas: o Idealismo ${ }^{3}$ e o Materialismo. Os idealistas respondem que a consciência, o pensamento, o absoluto, o espírito, a ideia (várias são as nomenclaturas dependendo do autor), é a base estruturante do universo. Os materialistas, por outro lado, respondem que a matéria vem primeiro. Imaginemos duas grandes árvores, com troncos sólidos que foram se desenvolvendo de forma distinta. Seus galhos e ramificações foram crescendo ao longo de mais de dois mil anos de história filosófica. Com essa metáfora, podemos imaginar a complexidade e as ramificações em que estas duas abordagens se apresentam hoje. Abordar esta trajetória não é a pretensão deste artigo. Buscamos pontuar que, indiretamente, precisamos considerar as origens, as bases epistemológicas que refratam diferentes abordagens e perspectivas.

O Positivismo ${ }^{4}$, que orientou boa parte do conhecimento científico até a década de 1970, tem sua base no Idealismo Subjetivo. O conhecido "pai" desse sistema de pensamento foi Augusto Comte, notadamente após a publicação, em 1852, de Discurso sobre o espírito positivo. Citamos esta obra para exemplificar que o termo discurso não é exclusivo de nenhuma teoria. $\mathrm{O}$ que o pesquisador deve saber distinguir é a concepção, o seu significado dentro de determinada corrente epistemológica.

Sabemos que os fundamentos epistemológicos da ATD se assentam em duas correntes filosóficas: a Fenomenologia e a Hermenêutica, ambas derivadas do Idealismo. A Fenomenologia 5 tem sua base estruturada no estudo dos fenômenos, seu principal

\footnotetext{
${ }^{3}$ Existe diferença entre Idealismo Subjetivo e Objetivo. No Idealismo Subjetivo, a única realidade "é a consciência do sujeito, o conjunto de suas sensações, vivências, estados de ânimo e ações". Este Idealismo, no século XX, terá uma série de desdobramentos e representantes teóricos. Para Triviños (1987), a maioria deles, seguramente, está situada no Positivismo (Mach, Avenarius); nos empiristas lógicos; na Filosofia Analítica, cuja forma dominante na Inglaterra se denomina Linguística; na Filosofia da Vida (Nietzsche, Spengler, Bergson); no Pragmatismo, com destaques ao neopragmatismo de Quine, Goodman, White; e, por fim, no Existencialismo (Heidegger, Sartre, Jaspers e outros). O Idealismo Objetivo é principalmente representado por Hegel e concebe o mundo a partir da ideia, da consciência, do espírito absoluto. Outros pensadores são influenciados pelo Idealismo Objetivo são "Mounier, Lacroix e Ricouer" (TRIVIÑOS, 1987, p. 20).

${ }^{4}$ O Positivismo passou por três fases: o clássico de Comte; o empiriocriticismo de "Avenarius e Mach e o neopositivismo, que compreende: o positivismo lógico, o empiricismo lógico, o anatomismo lógico, a filosofia analítica, o behaviorismo e o neobehaviorismo; o pragmatismo e o instrumentalismo ou naturalismo humanista" (TRIVIÑOS, 1987, p. 33-34).

$5 \mathrm{Na}$ Fenomenologia também encontramos diversas correntes. Dentre as quais podemos citar o Existencialismo ateísta de Heidegger, Sartre e Merleau-Ponty; a Fenomenologia das essências de Heidegger e Max Scheler; e a Fenomenologia de natureza sociológica (TRIVIÑOS, 1987).
} 
expoente é Husserl. A Fenomenologia não se interessa pela historicidade dos fenômenos, portanto tem uma dimensão a-histórica. "A fenomenologia exalta a interpretação do mundo que surge intencionalmente à nossa consciência. Por isso, na pesquisa, eleva o ator, com suas percepções dos fenômenos, sobre o observador positivista" (TRIVIÑOS, 1987, p. 47).

A perspectiva hermenêutica propicia compreensões e interpretações dos fenômenos, com destaque para os processos linguísticos que reconstroem a análise textual. "A racionalidade hermenêutica reassume-se como sabedoria prática que não só interpreta a linguagem, os símbolos, os discursos e os textos, mas recria em ato a pluralidade de sentidos" (TAVARES, 2018, p. 437).

$\mathrm{Na}$ perspectiva de Paul Ricoeur (2000), a Hermenêutica possibilita uma interpretação mais ampla, considerando que o discurso, enquanto fenômeno da linguagem, propicia a compreensão da experiência humana.

O discurso é um acontecimento da linguagem, um complexo de símbolos que escondem, dentro de si, mistérios que precisam de ser desvelados. Essa é a função da hermenêutica: desvelando e revelando os sentidos do mundo humano presentes, muitas vezes, de um modo latente, na linguagem, no discurso e nos símbolos que os constituem, considerando que os símbolos são expressões de duplo sentido e que manifestam as múltiplas relações do ser humano consigo próprio, com os outros e com o mundo (TAVARES, 2018, p. 438).

Na perspectiva hermenêutica, o importante é a compreensão e isso se faz presente na linguagem, na relação entre os sujeitos, nos textos. Ou seja, a questão central é a compreensão, e a linguagem tem uma função fundamental na interação comunicativa.

O fenômeno da compreensão e da maneira correta de se interpretar o que se entendeu não é apenas, e em especial, um problema da doutrina dos métodos aplicados nas ciências do espírito. [...] $\mathrm{Na}$ sua origem, o fenômeno hermenêutico não é, de forma alguma, um problema de método. O que importa a ele, em primeiro lugar, não é estruturação de um conhecimento seguro, que satisfaça aos ideais metodológicos da ciência - embora, sem dúvida, se trate também aqui do conhecimento e da verdade. Ao se compreender a tradição não se compreende apenas textos, mas também se adquirem juízos e se reconhecem verdades (GADAMER, 1999, p. 32).

O Materialismo filosófico marxista ${ }^{6}$ teve influências do Idealismo Objetivo de Hegel, mas inverte sua lógica ao propor a análise da sociedade a partir das bases materiais do modo de produção capitalista. As categorias do método do Materialismo histórico são: totalidade, historicidade e contradição. Nenhuma visão é totalmente pura e estanque, ou

\footnotetext{
${ }^{6}$ Iremos retomar a discussão sobre o Materialismo histórico na quarta seção do presente artigo. O Marxismo pode ser caracterizado por quatro fases: a primeira, inaugurada por Marx; uma segunda, com as contribuiç̧ões de Engels; a terceira, a partir de Lenin; e a quarta, numa perspectiva contemporânea (TRIVIÑOS, 1987).
} 
seja, elas vão se modificando ao longo da história e do desenvolvimento científico e tecnológico. Uma corrente influencia a outra; os autores dialogam entre si, tanto concordando quanto discordando; eles propõem novas perspectivas para compreender, interpretar e analisar o objeto de estudo ou pesquisa.

Para melhor compreensão da lógica de construção deste artigo, a partir do que apresentamos nesta introdução - a identificação das duas fases da produção teórica de Roque Moraes; as bases filosóficas do Idealismo e do Materialismo -, procuramos desenvolver a reflexão em mais quatro tópicos. Na seção a seguir, caracterizamos as aproximações e os distanciamentos da ATD com a Análise de Conteúdo, tendo como referencial Bardin ([1977] 2004). Posteriormente, na terceira seção, a partir de um levantamento empírico, caracterizamos duas concepções para o termo "discurso" na ATD: o discurso social e o discurso textual. Na quarta parte, apresentamos o "guardachuva" das análises de discurso e pontuamos a diferença entre autores que contribuem para os estudos do discurso para os teóricos da AD. Tendo presente que os autores da ATD consideram-na como estando no meio-lugar entre dois extremos, na quinta seção deste trabalho, discutimos a possibilidade de que um dos extremos seja a AD francesa de Michel Pêcheux e apresentamos alguns conceitos básicos que compõem o dispositivo teórico e analítico; desta forma, procuramos dar visibilidade a algumas diferenças em relação à ATD.

\section{Moraes, primeira e segunda fase}

A AC tem suas origens no método científico cujo rigor metodológico baseia-se na tradição positivista. Nesta perspectiva, são privilegiadas a pesquisa de abordagem quantitativa, a objetividade dos dados e a neutralidade do pesquisador, sem deixar de ser utilizada nas pesquisas de cunho qualitativo. Segundo Navarro e Díaz (1994), a AC é um método de investigação social que, como outras técnicas de análise textual, se preocupa em ter aplicabilidade nas pesquisas de abordagem qualitativa.

Lembrando que a AC não é de autoria exclusiva de Bardin ([1977] 2004), ela realiza uma sistematização do que vários pensadores da época discutiam sobre a análise. Para Bardin, a AC é "um conjunto de instrumentos metodológicos cada vez mais subtis [sic] em constante aperfeiçoamento, que se aplicam a 'discursos' (conteúdos e continentes) extremamente diversificados" (BARDIN, [1977] 2004, p. 7). Por que destacamos este conceito? Para demonstrar que o termo discurso também é empregado 
ao longo da obra de Bardin; inferimos, a partir daí, que o termo discurso não é exclusividade de uma ou outra abordagem teórica. Por esse motivo, dependendo da abordagem em que é utilizado, apresenta significados completamente diferentes, e saber distingui-los é o desafio posto ao pesquisador-analista. Esta é a concepção base com que os analistas de discurso trabalham: não compreender o termo em si, mas, sim, a partir do significado que lhe é atribuído a partir de suas bases teóricas e epistemológicas. Some-se a isso que, na perspectiva de Pêcheux, o sentido de um termo sempre poderá ser (ou vir a ser) outro.

A definição mais conhecida de AC faz referência a um "conjunto de técnicas de análise das comunicações" (BARDIN, ([1977], 2004, p. 27); mas o que exatamente significa dizer técnicas de análise? Que a AC, por si, só é uma "designação genérica de análise de conteúdo" (BARDIN, [1977] 2004, p. 11) porque se compõe de vários tipos de técnicas que podem ser escolhidas pelos pesquisadores de acordo com o propósito de suas pesquisas.

E quais são estas técnicas que compõem o conjunto da Análise de Conteúdo? A maior parte do livro de Bardin explica a técnica categorial ou temática, apresentando os procedimentos do método e citando exemplos. Apresentam-se, também, as técnicas de análise de avaliação, análise de enunciação, análise de expressão, análise de relações e a análise do discurso ${ }^{7}$. Portanto, quando se diz que a AC é uma expressão genérica, o pesquisador deve ter consciência de que é necessário especificar qual das técnicas foi escolhida; caso contrário, pouco será dito sobre o processo de análise realizado.

A AC enfoca a expressão-objeto (NAVARRO; DÍAZ, 1994), que pode ser classificada, separada. Nesse sentido, a expressão-objeto pode designar palavras, enunciados, expressões, unidades de análise, categorias e unidades de contexto. Pode, inclusive, ser o objeto que é selecionado para a análise. Na mesma esteira de pensamento, a AC é uma metodologia investigativa, concepção compartilhada por Moraes e Galiazzi (2007).

Em Bardin ([1977] 2004) o processo de categorização ocorre pela frequência e pela classificação das unidades de sentido. A importância das categorias é hierarquizada pela frequência utilizada; ou seja, quanto mais aparece, mais se torna importante. Daí resulta que os processos de inferência e de tratamento de análise devem estar de acordo com a classificação de forma decrescente. Para o processo de categorização, Bardin

\footnotetext{
${ }^{7}$ Vale destacar, entretanto, que a concepção de Bardin acerca da $\mathrm{AD}$ de base pecheutiana não é a mesma que apresentaremos nas reflexões deste artigo.
} 
([1977] 2004), apresenta basicamente duas etapas: a unitarização e o seu agrupamento, resultando na categorização. O número de categorias depende da classificação realizada pelo pesquisador. Posteriormente, o processo de inferência é fundamental para a obtenção do resultado da análise.

Em sua primeira fase, Moraes, baseado na AC de Bardin ([1977] 2004), apresenta algumas diferenças em relação à referida autora; não quanto à concepção de análise, mas ao procedimento metodológico na aplicação da técnica.

Sabemos que o processo de categorização é a espinha dorsal da $\mathrm{AC}$, e a contribuição e originalidade de Moraes (1994) está em propor um processo de classificação diferente de Bardin para se chegar à categorização. Moraes desassocia a necessidade da frequência quantitativa para a definição das categorias. Este processo de categorização é realizado de forma processual e classificatória, em várias etapas: unitarização, categorias: inicial, intermediária e final. Após a unitarização, ocorrerá o primeiro agrupamento, resultando na formação das categorias iniciais. $\mathrm{O}$ agrupamento destas categorias irá resultar nas categorias intermediárias, e o agrupamento destas últimas resultará nas categorias finais. É um processo de desmembramento que leva ao detalhamento da classificação das categorias. Nesse processo, apresenta-se claramente o procedimento de descrição das categorias para, posteriormente, se chegar à interpretação.

Nos processos de categorização e de descrição, apresentados na primeira fase de Moraes para os pesquisadores que conhecem a ATD, já identificam algumas semelhanças, porém existem diferenças significativas, decorrentes da concepção adotada na segunda fase. Ou seja, a ATD procura se distanciar do tecnicismo da perspectiva bardiniana, buscando um viés compreensivo e interpretativo do texto discursivo nas bases da Fenomenologia e da Hermenêutica.

A abordagem da ATD é, por excelência, qualitativa (MORAES, 2020), rompendo com os pressupostos da primazia do paradigma quantitativo e positivista. Esta abordagem qualitativa afeta o próprio pesquisador, porque rompe radicalmente com a ideia de neutralidade. Ao trazer o pesquisador para o centro do processo metodológico da ATD, sua autoria é destacada (MORAES, 2020). Assim, o pesquisador é o autor e, para tanto, deve ter ocorrido uma apropriação e uma incorporação da análise; ou seja, a autoria se desloca: do texto para o autor-pesquisador da análise. É uma concepção profundamente hermenêutica.

Aliás, esta é a principal característica de originalidade da ATD, pois ressignifica a função do pesquisador que interpreta o texto para o pesquisador-autor do texto. E não 
somente isso: propõe-se, assim, que o próprio processo da ATD resulte numa mudança interna do analista, pois o processo se torna auto-organizado, implicando num novo processo de aprendizagem do próprio pesquisador, "com foco especial nas transformações dos pesquisadores ao longo do processo" (MORAES; GALIAZZI, 2007, p. 18). Neste sentido, vale ressaltar que a ATD inova em relação a outras perspectivas de análise, porque o pesquisador também se torna protagonista do processo. Ao mesmo tempo em que analisa o texto, tem a finalidade de se autotransformar, resultando em novas compreensões do objeto de análise, que até então não haviam sido percebidas. Portanto, para que a ATD se realize plenamente, é necessário passar pelo processo de autotransformação; para atingir sua última etapa, é exigido o "autoconhecimento de quem pesquisa" (MORAES, 2020, p. 12). ATD ainda não para aí; ela vai além, propondo que este processo resulte em novas teorias.

Após esta contextualização do que chamamos primeira e segunda fase de Moraes, passemos a refletir sobre o significado de discurso na concepção da ATD.

\section{Discurso na ATD: o discurso social e o discurso textual}

Na ATD, o termo discurso está presente em todos os textos, porém nem todos apresentam o mesmo significado. A partir de uma análise empírica, procuramos identificar o emprego do termo discurso e os significados associados a ele. Nesse processo, destacamos um duplo significado, de onde decorrem as denominações discurso social e discurso textual. Trataremos dessa especificidade nos tópicos a seguir.

\subsection{Discurso social}

Procuramos entender melhor as associações vinculadas ao termo discurso social, (MORAES; GALIAZZI, 2007), a primeira característica que encontramos é que ele se opõe à concepção de um discurso individual, pessoalizado. Aí o leitor poderá se perguntar: na ATD, o sujeito é concebido como protagonista do seu discurso. Então, como não se refere ao individual? O conhecedor da ATD tem uma percepção correta, e esta decorre principalmente de sua reconstrução enquanto autor do próprio texto e da análise. Isso implica também o protagonismo individual.

Porém, quando nos referimos à característica do social em oposição ao individual, queremos dizer que o discurso a que se refere não está de forma explícita no texto. Assim, ao considerar o texto (o manifesto), é preciso remetê-lo a uma dimensão maior, em que a 
linguagem é (socialmente) produzida; portanto, entram em cena as representações sociais que circundam o texto.

Nesse sentido, não nos referimos à autoria individual do autor que produziu o texto, mas, sim, ao fato de que o discurso, objeto de análise desses pesquisadores, não está desassociado do contexto social que lhe atribui significados. O discurso é produzido socialmente e, direta ou indiretamente, é "incorporado" (materializado) ao texto que está sendo analisado.

O discurso social não se localiza num enunciado específico, ele se refere a uma ideia que está sendo comunicada, Moraes e Galiazzi (2007, p. 115) ressaltam que não apenas se referem à ideia, mas “às relações múltiplas entre elas”. Esta concepção de discurso remete a uma percepção que não perde de vista o todo, que enxerga além das partes que foram fragmentadas para a análise. O discurso remete, assim, aos "discursos a que pertencem" (MORAES; GALIAZZI, 2007, p. 115), o que significa dizer que o discurso sempre terá como referencial as relações entre os enunciados em que fora produzido, daí decorre o pertencimento a um gênero de discurso. Por isso, o sentido diz respeito ao "discurso em si", como lemos a seguir:

[...] o interesse de pesquisas que utilizam a análise textual discursiva não são as manifestações individuais de sujeitos em um discurso, mas o discurso em si. Por esse motivo não importa tanto manter o todo de uma voz se manifestando no discurso, mas a integração das manifestações de diferentes sujeitos num determinado gênero discursivo. Examinam-se os diferentes enunciados para compreender a complexidade de relações que podem ser estabelecidas entre eles na constituição do discurso (MORAES; GALIAZZI, 2007, p. 115).

Não perder de vista o todo a que o discurso pertence está relacionado com a identificação do gênero discursivo, com a percepção de que o discurso não está dissociado do sistema complexo da linguagem. Nesse sentido, na ATD os gêneros discursivos "podem ser entendidos como sistemas complexos auto-organizados em circuitos recursivos, autopoiéticos. Fragmentar estes sistemas é destruí-los. Cada parte isoladamente tem muito pouco a dizer sobre o todo" (MORAES; GALIAZZI, 2007, p. 152). Os gêneros discursivos se relacionam com os "modos" de discurso, o "discurso poético, discurso científico, discurso religioso, discurso especulativo, discurso metafórico" (RICOEUR, 2000, p. 392).

Na perspectiva hermenêutica, a compreensão do discurso na relação com o todo e com o sistema complexo da linguagem, implica compreender o discurso para além da palavra e da frase, e isso porque ele integra uma realidade a ser analisada e interpretada. 
A passagem ao ponto de vista hermenêutico corresponde à mudança de nível que conduz da frase ao discurso propriamente dito (poema, narração, ensaio, etc. [...] A metáfora é uma figura do discurso, focalizado sobre a palavra. [...] Essa transição da semântica à hermenêutica encontra sua justificação mais fundamental na conexão em todo discurso entre o sentido, que é sua organização interna, e a referência, que é seu poder de referir-se a uma realidade fora da linguagem (RICOEUR, 2000, p. 13).

O discurso social também é mencionado nas diversas etapas metodológicas da ATD. No que diz respeito à definição do corpus, a partir das escolhas e determinação da unitarização, a etapa da categorização também se torna importante para a compreensão discursiva. Esta compreensão discursiva ocorre na relação das partes com o todo, ao final do processo. "Cada categoria construída representa um aspecto dos textos que podem ajudar na construção de uma compreensão mais complexa dos discursos em que os textos foram produzidos" (MORAES; GALIAZZI, 2007, p. 121). O contexto desta afirmação remete ao discurso social, pois a compreensão da constituição do corpus, da unitarização e da categorização remete ao discurso externo ao texto e possibilita a sua compreensão.

O passo seguinte à categorização com a descrição e a interpretação das categorias é a produção do metatexto, que deve permitir outra compreensão do texto. "O mesmo processo permite ao pesquisador uma intervenção nos discursos a que sua produção se refere" (MORAES; GALIAZZI, 2007, p. 122).

A qualidade da análise diz respeito à qualidade do material e ao processo desenvolvido, principalmente na etapa de elaboração dos metatextos. Nesta etapa, o pesquisador considera o discurso coletivo das condições de produção em que o texto foi elaborado, pois esta é a referência para significar o discurso coletivo e possibilitar a compreensão de novos significados. "Representa a intervenção em discursos coletivos que a pesquisa realizada possibilita ao pesquisador" (MORAES; GALIAZZI, 2007, p. 114). O resultado do processo da ATD irá permitir novas compreensões dos discursos analisados, "[...] no sentido de atingir uma compreensão mais complexa dos fenômenos e dos discursos a partir dos quais foram produzidos" (MORAES; GALIAZZI, 2007, p. 114). Aqui se apresenta a ideia não só de discurso social, referente a uma realidade vivida, mas também ao discurso coletivo, o que nos parece ter o mesmo sentido que discurso social.

Cabe um destaque em relação à "autoria auto-organizativa", como a última etapa da ATD em que o pesquisador se torna sujeito do processo. Tal procedimento não ocorre de forma passiva nem se limita à análise dos dados, o pesquisador mesmo se torna o próprio "objeto" da análise no processo de auto-organização. Em outras palavras, de 
analista passa a ser também autor, como se a análise fundisse, no sujeito, o pesquisadoranalista-autor, formando uma única unidade de análise. Referindo-se ao processo de autoorganização, Moraes e Galiazzi (2007, p. 134) mencionam que esse tipo de “encaminhamento requer que o escritor assuma seu papel de sujeito histórico, capaz de intervir nos discursos que investiga, ao mesmo tempo em que assume a autoria de suas produções”. Esta autoria se expressa numa ousadia, processo em que o pesquisador expressa suas ideias e opiniões junto com as demais vozes que derivam da análise do textual. Sendo assim,

o pesquisador, ao assumir-se autor do que produz, exerce seu poder de sujeito competente, capaz de opinião própria e apto a intervir nos discursos em que se envolve $[\ldots]$ constituir-se em formas de intervenção nos discursos nos quais os textos são submetidos a análise se inserem [...] assumir-se como sujeito histórico, capaz de intervir nos discursos no sentido de sua reconstrução (MORAES; GALIAZZI, 2007, p. 135-137).

Processos discursivos se referem a tudo o que já foi comunicado e produzido socialmente. Nesse sentido, os textos que estão sendo analisados incorporam discursos proferidos de uma realidade social e, para que seja possível sua compreensão, é necessário um mergulho profundo, o pesquisador impregna-se no/do texto. Nesse sentido também, podemos dizer que o texto, em processo de análise e interpretação, é absorvido pelo analista, que torna possível reconstruí-lo. Esta reconstrução, entretanto, não se refere a uma descrição. O pesquisador, ao "mergulhar" na análise, é capaz de ressignificar o texto a ponto de gerar um novo processo, auto-organizado e que implica num autoaprendizado; somente assim é possível reconstruir novos discursos. Seu texto de análise, fruto do processo anterior de metatextos, produz um novo discurso, direcionando para novas compreensões e, até mesmo, para criação de novas teorias.

[...] a análise textual discursiva é um mergulho em processos discursivos, visando a atingir compreensões reconstruídas dos discursos, conduzindo a uma comunicação do aprendizado e desta forma assumindo-se o pesquisador como sujeito histórico, capaz de participar na interpretação e na constituição de novos discursos (MORAES; GALIAZZI, 2007, p. 111-112).

O processo da ATD somente se completa se, de fato, o pesquisador tornar-se autor por meio de um processo autoconstruído, o que implica novas aprendizagens e ressignificações. Ou seja, remete ao novo, àquilo que só foi possível ser captado porque passou por um processo analítico. Caso contrário, não seria realizado.

A partir do exposto, demonstrando que o discurso social não se refere ao texto de forma pontual através de uma frase, palavra, enunciado, mas, sim, que é expresso a partir de um contexto, da realidade em que funciona o sistema complexo da linguagem, 
podemos inferir que o discurso social apresenta uma natureza complexa e abstrata, resultando de uma comunicação produzida social e coletivamente. Com isso, vale destacar que o discurso social se refere à realidade.

No artigo Da noite ao dia: tomada de consciência de pressupostos assumidos dentro das pesquisas sociais, Moraes (2006) discute as escolhas que o pesquisador realiza e a relação que tece com a realidade. $\mathrm{O}$ autor defende uma perspectiva em que o sujeito é partícipe na construção desta realidade. "Nessa visão, realidade é o conjunto de nossas crenças e teorias, conscientes ou implícitas, nossas e dos que conosco convivem. Realidade é discurso. A realidade é construída na linguagem" (MORAES, 2006, p. 2). Portanto, podemos compreender que a relação entre o todo e as partes se faz na compreensão da realidade-linguagem-discurso, o que caracteriza o discurso social.

\subsection{Discurso textual como unidade de expressão do texto}

Dizemos análise textual para tratar de uma análise do texto. Toda a comunicação pode ser analisada sob a forma de texto, para que possa passar pelo processo metodológico. Porém, numa análise, não nos referimos somente ao texto, mas também às implicações e aproximações com a linguagem, à mensagem, ao discurso. Para Moraes e Galiazzi, "as análises textuais se concentram na análise de mensagens, da linguagem, do discurso, ainda que seu corpus não seja necessariamente verbal, podendo também referirse a outras representações simbólicas” (MORAES; GALIAZZI, 2007, p. 141).

Ao comentar que a pesquisa qualitativa trabalha com o texto, em oposição à pesquisa que trabalha com os números, "origina-se daí a denominação de análise textual, em que o sentido de texto aproxima-se de discurso [...] Desta forma a análise textual trabalha com textos, amostras de discursos [...]" (MORAES; GALIAZZI, 2007, p. 112). De forma geral, o discurso não é considerado sinônimo de outros termos, tais como fala, palavra, frase ou enunciado, muito embora a eles possa se referir. O discurso seria uma instância final, decorrente da progressão da palavra para a frase, chegando ao texto e, finalmente, ao discurso (RICOEUR, 2000). Em outras palavras, discurso é uma instância relacional, composta pelas unidades partícipes do sintagma linguístico.

Em outras palavras, o texto se refere a enunciados específicos que são utilizados para comunicar e argumentar uma ideia. Nesse sentido, chamamos de discurso textual porque, diferentemente do discurso social, que ocorre no âmbito abstrato e implica 
relações entre gêneros discursivos, o discurso textual é específico, concreto e se refere ao texto propriamente dito.

Podemos inferir que o discurso textual se refere ao processo concreto de análise. Ele está presente desde a primeira etapa, quando o texto é desconstruído, e atravessa o processo posterior de reconstrução. Também participa das demais etapas da ATD, com destaques ao processo de desdobramento e de classificação das categorias. Ele é visível (concretizado) por intermédio de palavras, frases, enunciados e auxilia no processo de descrição, interpretação e compreensão.

Ao ser definido e delimitado o corpus de análise, este já representa o discurso do material a ser analisado. Nesse sentido, "fazer análises qualitativas de materiais textuais implica assumir interpretações de enunciados dos discursos, a partir dos quais os textos são produzidos [...]" (MORAES; GALIAZZI, 2007, p. 113). Na ATD, nenhum processo de análise é capaz de dar conta da totalidade do fenômeno investigado, assim como "nenhum discurso pode ser descrito de modo integral" (MORAES; GALIAZZI, 2007, p. 132).

Ao se referir ao uso de metáforas, a partir da influência de Ricoeur (2000), podemos pensar em como elas podem ser utilizadas como mecanismos que ajudam a reconstruir os significados do discurso. Em outras palavras, "entende-se que o exercício do uso de metáforas é um modo interessante e criativo de expressar novos significados reconstruídos dentro do discurso" (MORAES; GALIAZZI, 2007, p. 134).

Podemos dizer que uma das contribuições da ATD é articular o termo discurso em duas perspectivas: uma relacionada ao discurso social, fazendo com que o analista não perca a dimensão da realidade e do contexto em que os textos são produzidos; e a outra do discurso textual, que convoca o pesquisador-analista a compreender o texto sob o olhar atento da articulação com a estrutura interna do texto.

Desse modo, podemos dizer que discurso social e discurso textual são perspectivas que se complementam e que podem ser compreendidas como indissociáveis. As duas perspectivas também estão interrelacionadas, quando articulam a parte (quando se analisa o discurso implícito e explícito do próprio texto, por exemplo) com o todo, relacionando ao contexto. Em outras palavras, o analista textual-discursivo tenta articular o todo e as partes, o interno e o externo, para a compreensão do fenômeno pesquisado, considerando que o resultado será uma auto-organização do próprio pesquisador, que vivencia a passagem de pesquisador para analista-autor. Ou seja, a análise textual discursiva convoca o pesquisador a passar por um processo de aprendizagem no decorrer da análise, 
sinalizando para a possibilidade de transformação do próprio pesquisador, realojando-lhe de uma perspectiva passiva para um lugar de protagonista do discurso-textual-social.

\section{Análises de discursos e suas múltiplas abordagens}

Consideramos o termo análise de discurso como um enunciado genérico que abrange uma diversidade enorme de correntes e autores, é necessário conhecer essas vertentes para então saber a qual delas fazer referência/filiar-se. Por isso, propomos utilizar o termo análises de discursos, de forma a evidenciar a pluralidade de abordagens que compõem esse dizer. As diferenças são significativas e fazem com que seja possível caracterizar cada uma delas. Imaginemos a figura de um grande "guarda-chuva", que pressupõe, na relação entre suas astes, um movimento em espiral:

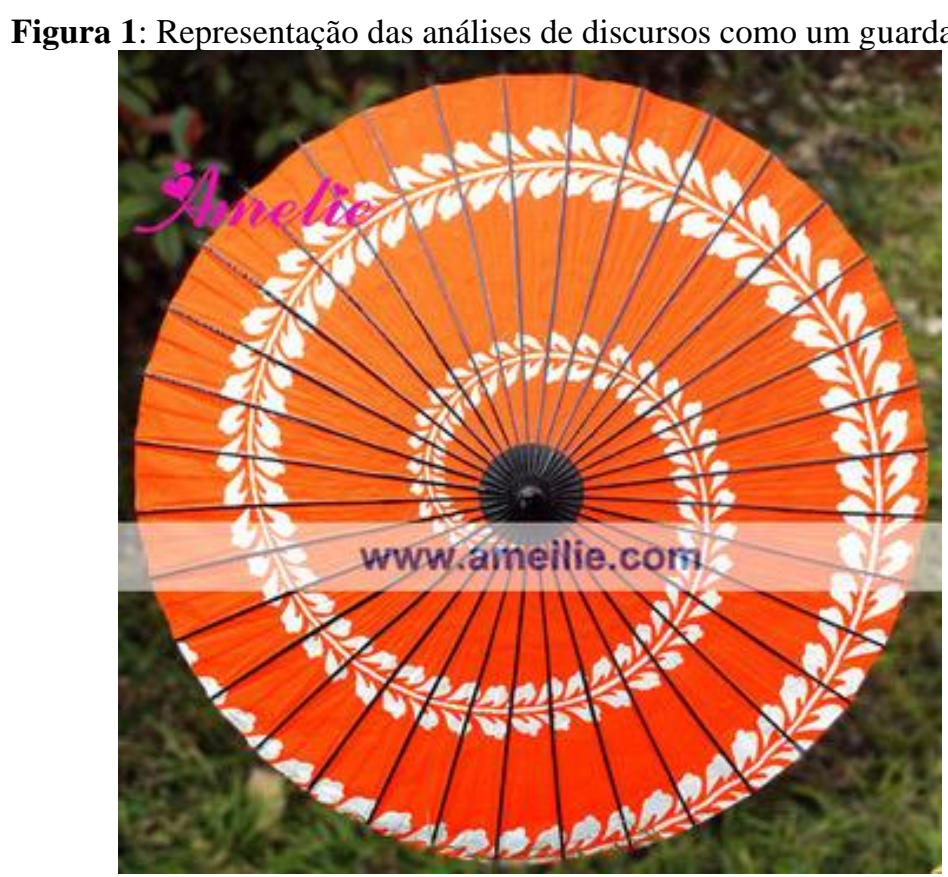

Fonte: www.amelie.com

Chamaremos este guarda-chuva de análises de discursos. Cada haste representa uma abordagem diferente, com seus campos conceituais devidamente delimitados. Partimos do pressuposto de que estas hastes são compostas pela diversidade.

Ao mesmo tempo, existe uma unicidade que permite dizer que todas aquelas diferenças podem ser filiadas ao mesmo guarda-chuva, mais amplo. Esta unicidade é a materialidade do texto, de natureza estritamente linguística, e para entender a materialidade no campo discursivo, é preciso encará-la como linguística e histórica. Daí 
decorre a concepção do materialismo ${ }^{8}$ histórico-dialético ${ }^{9}$ que atravessa os conceitos de materialidade e de discurso. Esta é a base filosófica que unifica todas as abordagens de análises de discursos. Mas o que significa dizer que há uma base material do discurso?

$\mathrm{Na}$ abordagem filosófica de origem materialista (em oposição à idealista), a forma de conceber o mundo e suas relações a partir da matéria é pautada pela concretude do real. Este real, por sua vez, é compreendido a partir do modo de produção da sociedade, das condições de produção material, das relações de produção (econômica, histórica, social, política, cultural) e da luta de classes. "Se na história da humanidade, a revolta é contemporânea à extorsão do sobre-trabalho é porque a luta de classes é o motor dessa história" (PÊCHEUX, 1997, p. 302). Trata-se da conjugação entre matéria e história numa relação contraditória e dialética, em constante movimento. Essa perspectiva nos permite analisar o sistema linguístico como uma prática social; nela, estão em disputa interesses antagônicos na defesa de diferentes projetos societários nos quais a ideologia opera.

Pensemos que uma referência à História, a propósito das questões linguísticas, só se justifica na perspectiva de uma análise materialista do efeito das relações de classes sobre o que se pode chamar as "práticas linguísticas" inscritas no funcionamento dos aparelhos ideológicos de uma formação econômica e social dada [...] (PÊCHEUX, 1997, p. 24).

O materialismo histórico-dialético convoca o pesquisador-analista a se posicionar diante da realidade, a ter um projeto de sociedade contra a exploração do trabalho, contra as injustiças sociais provocadas pelo modo de produção capitalista, contra as desigualdades sociais e contra qualquer forma de racismo, preconceito, xenofobia e discriminação. Portanto, o mundo material, exterior, tem um funcionamento independente do pensamento e da consciência do indivíduo, porque opera independentemente, a partir de suas forças e do modo de produção, o que, em última instância, impacta (determina) sobre o sujeito. Em outras palavras, o materialismo histórico-dialético "coloca a independência do mundo exterior (e do conhecimento objetivo de suas leis) em relação ao sujeito" (PÊCHEUX, 1997, p. 76).

Outro aspecto que estamos considerando como unicidade para compor a abordagem das análises de discursos é a oposição à compreensão de que a língua é um

\footnotetext{
${ }^{8}$ Neste artigo, enfocamos o materialismo histórico-dialético, mas cabe lembrar que existiram vários tipos de materialismo que foram surgindo ao longo da história e do pensamento científico: o materialismo ingênuo; o materialismo espontâneo; o materialismo mecanicista; o materialismo vulgar; o materialismo dialético e o materialismo histórico (TRIVIÑOS, 1987).

${ }^{9}$ Existem vários significados para o conceito de dialética, como a dialética de Aristóteles; a dialética de Hegel; a dialética de Kant; a dialética marxista etc. Neste artigo, fazemos referência à concepção de dialética oiunda do materialismo histórico.
} 
sistema a-histórico e uma estrutura que, como tal, torna-se o "objeto teórico da linguística” (PÊCHEUX, 1997, p. 23). Essa concepção foi estruturada ao longo dos séculos e comportou várias abordagens que, inicialmente, buscavam unificar a língua e a compreensão de um sistema linguístico com existência própria. No início do século XX, "tratava-se de uma luta diretamente linguística pela unificação fonológica, morfológica, sintática e lexical da língua inscrita na forma-nação, unificação que o estruturalismo, o funcionalismo, o generativismo [...] apreenderão como a unidade de um sistema" (PÊCHEUX, 1997, p. 25). Nessa perspectiva, Saussure, autor de inegável importância, inaugura a Linguística como ciência apartada das demais ciências sociais, ele "define o objeto dessa ciência, a língua. Isola, ou distingue esse objeto dos demais fatos da linguagem. Caracteriza linguagem em oposição à língua. Caracteriza a língua em oposição à fala, à escrita e a outros códigos de linguagem" (RODRIGUES, 2008, p. 8).

$\mathrm{Na}$ concepção saussuriana, a língua é um sistema, uma estrutura que funciona independentemente da ação imediata do sujeito falante, muito embora o signo esteja relacionado a processos associativos e a uma convenção social. Aqui, a língua cumpre a função de mediar o pensamento e a interação comunicativa entre os sujeitos.

O signo lingüístico é fruto da associação entre uma imagem acústica - o chamado significante - e um conceito - chamado significado. A imagem acústica seria uma espécie de representação psíquica dos fonemas de que se compõem o signo. Enquanto o conceito, longe de ser uma imagem do que quer que possa ser referido pela língua, está relacionado ao processo de construção do significado no pensamento. Essas duas faces do signo, uma vez associadas, compõem sua integralidade (RODRIGUES, 2008, p. 12).

Considerar a língua a-histórica e como um sistema linguístico, implica considerar que é possível a neutralidade, o distanciamento nas concepções do pesquisador. Ou seja, acredita-se na neutralidade para compreender o objeto de estudo. Ao se considerar o sistema linguístico a-histórico, concebe-se a estrutura desassociada das relações sociais e de poder que estruturam as bases da sociedade. Nesse viés, a língua é tratada como um fenômeno desvinculado da materialidade social, econômica, política e histórica que compõe as relações de produção. Ela é considerada como uma norma linguística abstrata, e o signo linguístico passa a ser associado ao pensamento e não às relações materiais de construção da infra e superestrutura da sociedade. Em outras palavras, a Linguística concebida desta forma refere-se a "uma ciência que estuda a língua como um sistema, [em que] abordam-se interlocutores não marcados social, ideologicamente ou historicamente" (SILVA, 2013a, p. 53). 
Em relação ao campo do discurso, podemos dizer que ele está inegavelmente atrelado à Filosofia da Linguagem, domínio de saber em que filósofos e pensadores de diversas áreas da ciência debruçaram-se para refletir sobre questões relativas à língua e à linguagem. Podemos, então, afirmar que é o debate em torno da linguagem e da língua que traz à tona o campo do discurso. Nesse quadro, e de posse dos pressupostos do materialismo histórico-dialético, percebemos que há, no discurso, uma oposição à concepção filosófica das correntes derivadas do Idealismo.

Sendo assim, é fundamental que o pesquisador-analista tenha conhecimento e consciência das diversidades conceituais e epistemológicas que constituem o campo dos estudos da linguagem, em suas distintas abordagens. As oposições entre essas abordagens geram diferentes linhas e perspectivas conflitantes, mesmo as que derivam da distinção original entre idealistas e materialistas. Não que exista um tronco "puro", entretanto, a partir desta origem comum, vão surgindo concepções que, mesmo usando o mesmo termo ou palavra (como discurso, por exemplo) operam diferentemente.

Considerando estes aspectos gregários como centrais para a construção da unicidade do guarda-chuva das análises de discursos, destacamos, também, as diferenças inerentes. Ainda que assumindo a perspectiva das análises de discursos, não podemos tratar das abordagens de forma simplista, como se todas elas apontassem para um único significado; dentre as hastes encontramos diferenças significativas. Desse modo, com as generalizações, corremos o risco de simplificar o que não é simplificável.

Abrindo o guarda-chuva das análises de discursos, o primeiro aspecto a ser destacado é saber distinguir os autores que contribuíram, de forma direta ou indireta, para os estudos do discurso dos teóricos que caracterizam diferentes abordagens da Análise de Discurso, sem deixar de perceber as influências entre eles.

São estudiosos das mais diversas áreas do conhecimento, como filósofos, cientistas sociais, linguistas e psicanalistas, cujas teorias não necessariamente versam sobre o discurso, mas dialogam com questões relacionadas a ele. Seus postulados, portanto, são utilizados por várias áreas do conhecimento. Dizemos estudiosos das teorias do discurso porque estes não buscam estudar a aplicabilidade do discurso enquanto técnica, método ou metodologia, nem muito menos a sua aplicação prática em pesquisas. Ainda temos que considerar as diferenças entre autores americanos, europeus, russos, entre outros. Alguns dos autores que contribuíram para os estudos do discurso e que influenciaram vários autores da análise de discurso são: Bourdieu, Gramsci, Althusser, Lacan, Foucault, entre outros. Ao produzir suas teorias, estes pensadores produzem um 
campo semântico conceitual que não deve ser utilizado de forma indiscriminada, ou como se todos tivessem a mesma concepção sobre os termos empregados. Pelo contrário, o uso consciente de suas terminologias indica uma apropriação teórica do pesquisador. A título de exemplo - porque foge do escopo deste artigo e, portanto, não estamos apresentando a teoria dos referidos autores -, indicamos algumas peculiaridades de cada autor e exemplificamos alguns dos seus termos mais utilizados, pelos autores da análise de discurso.

Althusser (1918-1990), filósofo franco-argelino, por seu turno, desenvolve alguns conceitos definidores e germinais, tais como ideologia, sobreterminação, interpelação ideológica, aparelhos ideológicos de Estado, sujeito e assujeitamento. “A ideologia tem o papel de sobredeterminar o sentido da ação social, na medida em que interpela o indivíduo como sujeito, ou seja, na medida em que o indivíduo se torna sujeito assujeitado pela ideologia" (SILVA, 2013b, p. 72). Esse autor terá forte influência nos aspectos teóricos da teoria de Michel Pêcheux ${ }^{10}$.

Lacan (1901-1981), psicanalista francês, realiza uma releitura de Freud. Os conceitos da Psicanálise irão produzir efeitos sobre como o discurso é concebido, uma “compreensão da noção de sujeito dividido, da noção de língua como sujeita a falhas, de discurso como efeito de sentidos e da noção de real como o impossível de tudo dizer" (MARIANI; MAGALHÃES, 2013, p. 101). Portanto, são fundamentais os conceitos de sujeito cindido, inconsciente, discurso como efeito de sentido, lapso e falha. $\mathrm{O}$ discurso revela que há uma influência do inconsciente e, por isso, existe uma ilusão do sujeito de ser autor do próprio dizer. Aqui, a autoria é questionada, ou seja, ela sempre deriva da produção social, sob a qual estamos imersos e que dizem respeito aos esquecimentos e à memória, cujo funcionamento se relaciona com o inconsciente. O sentido do discurso não é evidente e, por isso mesmo, é opaco, falho, podendo sempre ter outro sentido. Lacan terá grande influência na teoria pecheutiana.

Da obra de Foucault (1926-1984), filósofo francês, destacamos os conceitos de discurso na constituição dos saberes dos sujeitos, formação discursiva, enunciado, relações de poder, poder, conhecimento, instituições, genealogia e arqueologia. Os eixos principais de sua teoria são a formação dos saberes; os sistemas de poderes que regulam a prática (como o poder é exercido); e as formas nas quais os indivíduos podem e devem se reconhecer como sujeitos. A arqueologia foucaultiana analisa saberes do a priori

\footnotetext{
${ }^{10}$ Michel Pêcheux foi aluno de Althusser.
} 
histórico; ela indica os processos que tornaram possível na história uma configuração presente. Na sociedade, a produção do discurso é controlada, selecionada, organizada a partir do poder e dominação (FISCHER, 2013). Este autor terá forte influência na Análise de Discurso de Maingueneau.

Alguns dos conceitos que caracterizam a obra do filósofo italiano Antonio Gramsci (1891-1937) são: hegemonia, bloco histórico, sociedade civil, sociedade política, filosofia da práxis, estrutura, superestrutura, sociedade política, ideologia e opinião pública. No que diz respeito especificamente ao discurso, sua contribuição "enfatizou o papel do discurso propagado pelas instituições educacionais, religiosas, e de comunicação da (re)produção das ideologias e da construção da hegemonia por meio da propagação e da repetição de determinados discursos" (OLIVEIRA, 2013, p. 41). Sendo assim, o discurso tem efeito por meio do funcionamento ideológico que cria o consenso e a hegemonia.

Bourdieu (1930-2002) foi um sociólogo e filósofo francês. Alguns dos seus conceitos mais utilizados são: poder simbólico, controle do acesso ao discurso público, palavra como instrumento de poder, elites simbólicas, habitus, campo e mercado simbólico. Há uma produção dos discursos a partir do habitus, capital linguístico, a relação entre interlocutores. Uma vez que o produtor de discurso encontra-se em concorrência ou luta simbólica pelo poder, deve-se atentar para o habitus linguístico dos interlocutores, pois isso possibilita considerar a capacidade que eles possuem de utilizar as possibilidades oferecidas pela língua e avaliar as condições de uso (SILVA, 2013c). Bourdieu e Gramsci terão forte influência na Análise Crítica do Discurso.

Cabe comentar as contribuições para os estudos do discurso, na produção da Teoria Dialógica do círculo de Bakhtin, cujos nomes mais conhecidos, no Brasil, são Mikhail Bakhtin (1895-1975), Valentin Volóshinov (1895-1936) e Pavel Medvedev (1892-1938), entre outros. O grupo trabalhou com os conceitos de enunciado concreto, gêneros do discurso (tipos relativamente estáveis de enunciados), enunciação, signo (não o linguístico, mas, sim, o ideológico), ético (referente à vida humana), entonação, situação de interação (cronotopo, tema e valoração). Seu enfoque é uma abordagem dialógica da linguagem, no sentido de que estamos num estado permanente de dialogismo entre as vozes; ou seja, o discurso sempre será uma resposta ou antecipação de resposta à outra voz (implícita ou explícita, direta ou indireta, do presente ou do passado). Dessa forma, os enunciados proferidos sempre virão ou se destinarão a outros enunciados. O discurso dialógico é sempre resultado de condições sociais e históricas, que supõem uma interação 
entre vozes, o que faz com que nunca possamos falar sozinhos, pois sempre estaremos implicados numa outra voz (SILVA, 2013a). Enquanto contexto do enunciado, a enunciação sempre dialoga com os conflitos sociais, o que produz diferentes sentidos.

Das inúmeras abordagens que constituem o guarda-chuva da Análise de Discuso, destacamos as seguintes: a AD da linha francesa de Michel Pêcheux, que se diferencia da AD da linha francesa de Charaudeau e Maingueneau; a Análise Crítica do Discurso ou Estudos Críticos do Discurso, de Fairclough e Teun van Dijk (com diferenças entre ambos).

Charaudeau é um linguista francês, fundador da teoria Semiolinguística de Análise do Discurso. Alguns de seus conceitos são: contrato de comunicação; estratégia discursiva de persuasão (ethos, imagem; pathos, paixão; $\log o s^{11}$, argumentação); campo político, instância política e cidadã. Para ele, discurso é o texto em seu contexto (condições de produção), um ato da linguagem, fenômeno condicionado por elementos linguísticos e extralinguísticos. Suas análises enfocam o discurso político (SILVA, 2013d).

Maingueneau, linguista francês, distingue discurso de enunciado: este se refere ao caráter de unidade linguística, enquanto o discurso se refere a uma unidade de comunicação associada às condições de produção devidas. Há uma dependência em relação ao gênero do discurso, e um dos principais aspectos que o caracterizam são as condições de produção (SOARES et al., 2013). Alguns dos conceitos de Maingueneau são: enunciado, formação discursiva (na concepção de Foucault e não de Pêcheux), totalidade coerente. Embora seja um dos autores citados na Análise de Discurso da linha francesa, sua abordagem, em muitos aspectos, se diferencia daquela de Michel Pêcheux. Por isso, é importante ter um cuidado para não haver confusão entre os postulados dos dois autores.

A Análise Crítica do Discurso possui como representantantes principais Norman Fairclough e Teun van Dijk. Mesmo estando filiados à mesma corrente, existem diferenças entre esses dois autores.

Alguns dos conceitos principais de Fairclough, linguista britânico, são: prática social, poder, ideologia, consciência, nominalização, estrutura textual, gênero textual, forma híbrida de gêneros, tomada de turnos, concepção relações dialéticas entre discurso e práticas sociais, e o papel do discurso nas mudanças sociais. Fairclough trabalha com o

\footnotetext{
${ }^{11}$ As formas de persuasão ethos, pathos e logos, são originários de Aristóteles.
} 
modelo tridimensional: texto, prática discursiva e prática social. A prática social inclui os seguintes elementos: atividades, sujeitos e suas relações, instrumentos, objetos, tempo e lugar, formas de consciência, valores, discurso. A constituição do discurso emana de uma prática social a partir de estruturas sociais, incluindo as relações de poder (OLIVEIRA; CARVALHO, 2013).

Teun van Dijk é um linguista holandês. Consideramos que o aspecto que o distingue dos demais e confere particularidade à sua teoria é o trabalho com o conceito de sociocognição. A perspectiva sociocognitiva é de suma importância para quem trabalha na área educacional, já que inclui os aspectos cognitivos (elaborações mentais) na relação com a produção discursiva. Van Dijk propõe uma concepção da teoria sociocognitiva do discurso, inserida numa concepção interacionista. Outros conceitos também são referidos, tais como: macronível social ou estruturas sociais; poder; abuso de poder; macroposição, ideologia, modelos mentais, contexto, modelos contextuais, eracismo, entre outros. Seu objeto de estudo centra-se não somente no poder, mas no abuso de poder, o que implica nas formas como um grupo domina outro, estabelecendo uma relação de exaltação do endogrupo e de discriminação a tudo o que se refere ao exogrupo. Procura demonstrar como as desigualdades sociais são postas em prática no contexto social e político. Nesse sentido, a obra de van Dijk é uma análise crítica da reprodução discursiva do abuso de poder na perspectiva de denunciar as formas de dominação e subordinação de um grupo sobre outro. O propósito da análise crítica do discurso é contribuir para uma mudança social em favor dos grupos dominados. Não considera a análise crítica do discurso como um método, e sim como um tipo de investigação para analisar o discurso (DIJK, 2005).

Chamamos a atenção para o fato de que quando o pesquisador-analista escolhe um autor, assume a responsabilidade teórica de utilizar corretamente seus termos e conceitos, a partir da comunidade epistêmica a que se filia. E, mais ainda, é preciso saber as especificidades que diferenciam um (mesmo) termo de um autor para outro, ainda que abrigadas sob o mesmo guarda-chuva genérico de análises de discursos. Este rigor conceitual é fundamental para garantir a qualidade das pesquisas realizadas.

Com os autores apresentados até o momento, procuramos fazer uma pequena amostra do quanto, mesmo filiados ao guarda-chuva da $\mathrm{AD}$, cada teórico apresenta suas peculiarides e campo semântico próprio, sem esquecermos que ainda existem muitos outros autores e teorias. É necessário, portanto, que o pesquisador-analista nomeie a abordagem e o autor a que se filia, gerando um rigor conceitual necessário para garantir 
a qualidade teórica e analítica de suas produções acadêmicas. A seguir, resumimos alguns conceitos da AD de Michel Pêcheux, que se diferencia das abordagens já citadas.

\section{Análise de discurso de Michel Pêcheux}

Partimos do pressuposto de que a ATD se situa entre dois extremos - de um lado a Análise de Conteúdo e, de outro, a Análise de Discurso - e supomos, a partir daí, que esse extremo da AD tem como referência a Análise de Discurso da linha francesa de Pêcheux. Para melhor compreendermos esta análise, comentaremos alguns aspectos: o materialismo histórico-dialético como um dos pilares estruturantes que compõem o tripé da análise de discurso; e alguns de seus principais conceitos (discurso, ideologia, formação discursiva, posição-sujeito), que caracterizam o dispositivo teórico, ao mesmo tempo em que se tornam indissociáveis do dispositivo analítico.

O materialismo histórico-dialético é um dos eixos estruturantes da tríade que estrutura a análise do discurso, junto com a Psicanálise e a Linguística ${ }^{12}$. A assunção da materialidade como histórica é um dos pilares da $\mathrm{AD}$ porque nos permite compreender as relações de produção e das forças produtivas que estruturam a infraestrutura do modo de produção, esteira da formação social e econômica do capitalismo. Esta premissa permite considerar que o sujeito se constitui na (e da) história. O sujeito inscrito na história é tido como agente passivo, não como seu protagonista. Por outro lado, o sujeito da história se inscreve como agente, protagonista capaz de construir a própria história.

Na perspectiva materialista, o sujeito não é o centro da história; e sim as condições de produção e reprodução/transformação do sistema, cuja força propulsora é a contradição, o locus privilegiado da luta de classes. A luta ocorre a partir do surgimento de interesses antagônicos entre sujeitos que disputam projetos societários diametralmente opostos. Polos opostos, mas necessários e constitutivos desse modo de produção, em que a contradição é o real da história, aquilo que se é impossível de ser determinado, enquanto esfera constitutiva do sistema capitalista. Sendo assim, a densidade histórico-social em que se insere a luta de classes caracteriza as condições de produção do discurso, ou as condições sócio-históricas sob as quais são tecidos o tempo e o espaço da historicidade (a inscrição da história na língua).

\footnotetext{
12 Neste artigo, não enfocamos as questões referentes à Psicanálise lacaniana (conceitos como falha, equívoco, esquecimento, lapso, chistes, ato-falho, entre outras) e à Linguística.
} 
A historicidade se inscreve na língua. Pêcheux (1997) esclarece que a linguagem deve ser considerada a partir de suas marcas históricas, pois é na relação com as condições de produção que os sentidos se estabelecem. Orlandi (2012, p. 12) caracteriza a historicidade como a "materialidade histórica dos sujeitos e dos sentidos", pois a linguagem opera a partir da exterioridade constitutiva da história.

Mas não é possível compreender a história e a historicidade sem sua vinculação com a ideologia. A ideologia se constitui a partir da história. Por isso, não é possível compreendê-la sem considerar a materialidade das condições de (re)produção e transformação que movimentam a história.

Somos atravessados pela história e interpelados pela ideologia, ou seja, o indivíduo se torna sujeito através da interpelação ideológica. Nesse sentido, Pêcheux (1997) considera a ideologia como a condição sine qua non para a reprodução e transformação das relações de produção. A ideologia não é, entretanto, a única determinante do sujeito, pois existem condicionantes sociais, culturais, políticos e, principalmente, econômicos intricados nessa relação. Contudo, é certo que a ideologia desempenha uma função determinante na produção e reprodução do sistema capitalista.

Na teoria de Althusser, os aparelhos ideológicos de Estado (AIE) são esferas em que a ideologia se realiza, não como ideia, mas como prática social, reproduzindo a ideologia dominante, através das seguites instituições: educacional, familiar, religiosa, jurídico, sindical, da informação, político, cultural (ALTHUSSER, 1980). Pêcheux amplia esta concepção, demonstrando que a função da ideologia pode ser compreendida como contraditória na medida em que reproduz e transforma, ou seja, ao mesmo tempo em que funciona como reprodutora do sistema das classes dominantes, também se torna o lugar de resistência, de transformação das relações de dominação. Segundo Pêcheux, "os aparelhos ideológicos de Estado constituem, simultaneamente e contraditoriamente, o lugar e as condições ideológicas da transformação das relações de produção; de onde, a expressão reprodução/transformação que empregamos" (PÊCHEUX, 1997, p. 145).

Não existe uma forma homogênea ou simétrica na operacionalização da ideologia que ocorre através dos AIE; sua materialidade se configura no que Pêcheux (1997, p. 146) chama de formação ideológica: "a instância ideológica existe sob a forma de formações ideológicas". Dentro de uma formação ideológica, a função da ideologia é produzir a evidência de um discurso que produz um único sentido. É apagada, assim, a possibilidade do discurso ter múltiplos sentidos. Sendo assim, o sentido que a formação ideológica produz passa a ser óbvio e naturalizado, até mesmo banalizado, e é compartilhado no 
senso comum sem passar pelo crivo da criticidade. O sentido do discurso torna-se natural, até mesmo óbvio, e a obviedade não é da ordem da análise, do senso crítico. $\mathrm{Na}$ perspectiva pecheutiana, a função ideológica é tampar o furo da falha do discurso. É como se o discurso fosse homogêneo, exato, no sentido e na interpretação. A ideologia faz com que os discursos sejam aceitos como verdades únicas, que pareçam ser transparentes e, mais ainda, como uma evidência natural. Não há ideologia sem sujeito e vice-versa. Nas palavras de Pêcheux (1997, p. 149), “a categoria de sujeito é a categoria constitutiva de toda ideologia".

Segundo Orlandi (2012), a ideologia funciona como uma prática social que se projeta nas formações discursivas. Em suas palavras, "ideologia como prática material, como práxis, projetadas nas formações discursivas. Tensões, deslocamentos" (ORLANDI, 2012, p. 12, os destaques são da autora). Portanto, a formação ideológica está relacionada à formação discursiva.

A formação discursiva é "o lugar da constituição do sentido" (ORLANDI, 1997, p. 162) porque é caracterizada por uma matriz discursiva, em que os enunciados são compartilhados em sentidos parafrásticos. Em outras palavras, a formação discursiva regula "aquilo que pode e deve ser dito" (PÊCHEUX, 1997, p. 160), num determinado espaço em que os sujeitos são afetados pela mesma formação ideológica.

O processo discursivo é designdo como "o sistema de relações de substituição, paráfrases, sinonímias etc. que funcionam entre elementos linguísticos - significantes em uma formação discursiva dada" (PÊCHEUX, 1997, p. 161). Isso significa também que poderão existir várias formações discursivas, correspondendo, no plano da língua, às formações ideológicas.

Para o ingresso na formação discursiva, o sujeito é interpelado por uma formasujeito, que é o Sujeito revestido de historicidade. A forma-sujeito é a porta de entrada na formação discursiva, por isso ela caracteriza e identifica o discurso que abriga. A formação discursiva não pertence ao sujeito, porque é o sujeito que se identifica com ela, o que irá possibilitar posições sujeito diferentes, por vezes, conflitantes, mas ainda assim, pertencentes à mesma formação discursiva.

Para Pêcheux (1997, p. 162), o interdiscurso é o "todo complexo com dominante das formações discursivas, esclarecendo que também ele é submetido à lei de desigualdade-contradição-subordinação que caracteriza o complexo das [formações ideológicas]". O interdiscurso comporta todos os sentidos, tudo o que já foi dito, compondo um complexo de enunciados, ou seja, "um processo de produção de sentidos 
que está se movimentando na rede de constituição de sentidos (interdiscurso)" (ORLANDI, 2012, p. 13). É como se o interdiscurso fosse um conjunto de possibilidades de dizer que já foram ditas em outro lugar, em outras situações, mas que não estão sendo ditas naquele momento. Quando ditas, correspondem a uma determinada formação ideológica e, por consequência, a uma determinada formação discursiva. O interdiscurso é da ordem do anônimo porque funciona como um grande conjunto que "abriga" todos os dizeres, os que já foram ditos e os que ainda poderão ser ditos. Quando um enunciado é dito, efetivamente materializado, ele "sai" do plano do interdiscurso e "entra" na formação discursiva, passando a produzir determinados sentidos. $\mathrm{O}$ interdiscurso se relaciona com a memória discursiva (não é a memória cognitiva individual), que diz respeito a uma retomada, a uma repetição, aos ditos que compõem uma memória social, "essa memória, constituída pelo esquecimento, o interdiscurso, em que alguma coisa fala antes, em outro lugar e independentemente, tem a ver com o funcionamento da ideologia. E com o real da história" (ORLANDI, 2012, p. 14).

Os conceitos que mobilizam o dispositivo teórico determinam o dispositivo analítico da $\mathrm{AD}$, pois não são concebidos separadamente e sim construídos de forma dialética em todo o processo de análise. Aliás, a análise não está desassociada de todo o processo da pesquisa. Isso implica dizer que o dispositivo analítico é inseparável do dispositivo teórico. Não é possível dividí-lo ou categorizá-lo, pois é um processo que ocorre entrelaçado em espiral, como se imaginássemos a representação icônica do DNA, em que, embora seja possível distinguir elementos, não é possível separá-los.

\section{Considerações finais}

O fio condutor desta reflexão foram os significados atribuídos ao termo "discurso" sob duas perspectivas: sua especificidade em relação à ATD e os sentidos utilizados nas análises de discursos. Os tópicos de reflexão foram cinco: no primeiro, destacamos a importância de se identificar a origem filosófica das correntes epistemológicas. É extremamente importante que o pesquisador saiba distinguir conceitos a partir das diferentes correntes filosóficas. Pois, certamente, fica evidente que o uso de determinados termos pode não ter o mesmo significado para todas as abordagens; pelo contrário, a perspicácia do analista é saber identificar estas diferenças. Desta forma, procuramos demonstrar que o termo "discurso" é referido em todas as abordagens epistemológicas, porém, seus significados são distintos. 
O segundo tópico abordado foi a caracterização do que chamamos de "Moraes primeira fase", com aproximações com a análise de conteúdo e, ao mesmo tempo, o despontamento de diferenças significativas com relação à AC. Em "Moraes segunda fase", considera-se a produção teórica da ATD, cuja base epistemológica é a hermenêutica e a fenomenologia.

No terceiro tópico, apresentamos o resultado da pesquisa empírica que buscou identificar os significados atribuídos ao termo "discurso" na ATD. Procuramos demonstrar que existe uma dupla acepção sob esse termo, o que nomeamos de discurso social e de discurso textual, ambas correlacionadas. A proposta da ATD é original e podemos inferir que, enquanto metodologia a ser adotada pelo pesquisador, permite ainda que se constitua enquanto teoria, na possibilidade de não ser compreendida como um processo acabado. Pelo contrário, como um processo em devir, um constante reconstruirse. Para isso, destaca-se a última etapa da ATD, como possibilidade de se autocriar, de se autotransformar, tanto o pesquisador quanto a teoria.

No quarto tópico, procuramos apresentar panoramicamente algumas abordagens diferenciando autores que contribuíram com os estudos do discurso e que tiveram forte influência nos teóricos de diferentes abordagens da Análise de Discurso. No quinto tópico, trouxemos alguns conceitos básicos do dispositivo teórico da $\mathrm{AD}$ de Michel Pêcheux, e que são indissociáveis do dispositivo analítico.

Nesse artigo, partimos do princípio que tanto a Análise de Conteúdo quanto a Análise de Discurso são nomenclaturas genéricas e que o pesquisador deve especificar a escolha realizada. Nossa perspectiva não é tratar os tipos de análise como escolhas maniqueístas, ou seja, afirmar que um tipo de análise é bom e outro ruim. Trata-se, isto sim, de escolhas conscientes em que o pesquisador se identifica mais com uma do que outra, em função, principalmente, de uma teoria que corresponda ao seu objeto de pesquisa. Qualquer das escolhas tem o seu constructo epistemológico e "ampara" o pesquisador a ter um rigor científico metodológico de aplicação nas pesquisas qualitativas.

Procuramos demonstrar que a escolha deve ser consciente, tendo o pesquisador conhecimento para determinar as origens e diferenças entre os tipos de análise. Portanto, quando questionado sobre o tipo de análise, um pesquisador deve ter o rigor científico de responder: estou usando a Análise de Conteúdo a partir da técnica (categorial/temática; ou análise de avaliação; ou análise da enunciação; ou análise da expressão; ou análise das relações); ou estou utilizando a Análise de Discurso a partir da abordagem (da linha 
francesa de Michel Pêcheux; ou da análise da linha francesa de Maingueneau ou Charaudeau; ou da análise crítica do discurso de Dijk, entre outros).

Cabe destacar que o parâmetro aqui adotado foi considerar que a ATD insere-se no entrelugar da Análise de Conteúdo de Bardin, e da Análise de Discurso de Pêcheux, e que, em relação a ambas, apresenta várias singularidades. Poderiam ter sido outras as escolhas epistemológicas, o que seria um estímulo para a produção de outros artigos. Por fim, podemos compreender o termo discurso como se estivéssemos olhando para a ponta de um iceberg. Aos poucos, nos damos conta da sua complexidade e das múltiplas possibilidades de sentido a partir das bases epistemológicas que se filiam. Desvendar, compreender e analisar para além da ponta do iceberg: eis o desafio do analista de discurso.

\section{Referências}

ALTHUSSER, L. Ideologia e Aparelhos Ideológicos do Estado. 3. ed. Portugal: Editorial Presença, 1980.

BARDIN, L. Análise de Conteúdo [1977]. 3. ed. Lisboa: Edições 70, 2004.

DIJK, T. A. V. Discurso, notícia e ideologia: estudos na análise crítica do discurso. Porto: Campo das Letras, 2005.

FISCHER, R. M. B. Foucault. In: OLIVEIRA, L. A. (org.). Estudos do Discurso: perspectivas teóricas. São Paulo: Parábola Editorial, 2013. p. 123-152.

GADAMER, Hans-Georg. Verdade e método. 3 ed. Petrópolis: Vozes, 1999.

MARIANI, B.; MAGALHAES, B. Lacan. In: OLIVEIRA, L. A. (org.). Estudos do discurso: perspectivas teóricas. São Paulo: Parábola Editorial, 2013. p. 101 - 122.

MORAES, R. Análise de conteúdo: limites e possibilidades. In: ENGERS, M. E. A. (org). Paradigmas e metodologias de pesquisa em educação. Porto Alegre: EDIPUCRS, 1994. p. 103-111.

MORAES, R. Da noite ao dia: tomada de consciência de pressupostos assumidos dentro das pesquisas sociais. Porto Alegre: EDIPUCRS, 2006.

MORAES, R. Mergulhos discursivos: análise textual qualitativa entendida como processo integrado de aprender, comunicar e interferir em discursos. In: MORAES, Roque; GALIAZZI, Maria C. Análise textual discursiva. Ijuí: Unijuí, 2007, p. 111 - 138.

MORAES, R.; GALIAZZI, M. C. Análise textual discursiva: análise de conteúdo? Análise de discurso? In: MORAES, R.; GALIAZZI, M. C. Análise textual discursiva. Ijuí: Unijuí, 2007. p. $139-162$. 
MORAES, R. Avalanches reconstrutivas: Movimentos dialéticos e hermenêuticos de transformação no envolvimento com a análise textual discursiva. Revista Pesquisa Qualitativa, São Paulo, 2020, no prelo.

NAVARRO, P.; DÍAZ, C. Análisis de contenido. In: DELGADO, J. M.; GUTIÉRREZ, J. (org.). Métodos y técnicas cualitativas de investigación em ciências sociales. Madrid: Editorial Sintesis Psicologia, 1994, p. 177- 224.

OLIVEIRA, L. A. CARVALHO, M. A. B. Fairclough. Estudos do discurso: perspectivas teóricas. São Paulo: Parábola Editorial, 2013. p. 281-310.

ORLANDI, E. Análise de discurso: princípios e procedimentos. 5. ed. Campinas: Pontes, 2012. PÊCHEUX, M. Semântica e discurso: uma crítica à afirmação do óbvio [1975]. Campinas: Unicamp, 1997.

RICOEUR, P. A metáfora viva [1975]. São Paulo: Edições Loyola, 2000.

RODRIGUES, R. da S. V. Saussure e a definição da língua como objeto de estudos. ReVEL, [S.I.], edição especial, n. 2, p. 01-25, 2008. Disponível em: https://bit.ly/38mdvom. Acesso em: 5 out. 2020.

SILVA, A. P. P. de F. Bakhtin. In: OLIVEIRA, L. A (org.). Estudos do discurso: perspectivas teóricas. São Paulo: Parábola Editorial, 2013ª . p. 45 - 70.

SILVA, J. O. Althusser. In: OLIVEIRA, L. A. (org.). Estudos do discurso: perspectivas teóricas. São Paulo: Parábola Editorial, 2013b. p. 71 - 101.

SILVA, J. O. Bourdieu. In: OLIVEIRA, L. A. (org.). Estudos do discurso: perspectivas teóricas. São Paulo: Parábola Editorial, 2013c. p. 153 - 182.

SILVA, J. O. Charaudeau. In: OLIVEIRA, L. A. (org.). Estudos do discurso: perspectivas teóricas. São Paulo: Parábola Editorial, 2013d. p. 235 - 260.

SOARES, A. F. et al. Maingueneau. In: OLIVEIRA, L. A. (org.). Estudos do discurso: perspectivas teóricas. São Paulo: Parábola Editorial, 2013. p. 261 - 280.

TAVARES, M. Paul Ricoeur e um novo conceito de interpretação: da hermenêutica dos símbolos à hermenêutica do discurso. Veritas, Porto Alegre, v. 63, n. 2, p. 436-457, maio.ago. 2018.

TRIVIÑOS, A. N. Introdução à pesquisa em ciências sociais: a pesquisa qualitativa em educação. São Paulo: Atlas, 1987.

Recebido em: 09 de novembro de 2020.

Aceito em: 17 de novembro de 2020. 